\title{
Analysis of Manufacturing-Induced Defects and Structural Deformations in Lithium-Ion Batteries Using Computed Tomography
}

\author{
Yi Wu ${ }^{1,2, *}$, Saurabh Saxena ${ }^{2}$ (D), Yinjiao Xing ${ }^{2}$, Youren Wang ${ }^{1}{ }^{(\mathbb{D}}$, Chuan $^{2}{ }^{3}$, Winco K. C. Yung ${ }^{4}$ \\ and Michael Pecht ${ }^{2}$ \\ 1 College of Automation Engineering, Nanjing University of Aeronautics and Astronautics, \\ Nanjing 211106, China; wangyrac@nuaa.edu.cn \\ 2 Center for Advanced Life Cycle Engineering (CALCE), University of Maryland, \\ College Park, MD 20742, USA; saxenas@umd.edu (S.S.); yxing3@umd.edu (Y.X.); pecht@umd.edu (M.P.) \\ 3 National Research Base of Intelligent Manufacturing Service, Chongqing Technology and Business \\ University, Chongqing 400067, China; chuanli@ctbu.edu.cn \\ 4 Department of Industrial and System Engineering, The Hong Kong Polytechnic University, Kowloon, \\ Hong Kong, China; wincokc.yung@polyu.edu.hk \\ * Correspondence: ywu90105@umd.edu
}

Received: 1 March 2018; Accepted: 9 April 2018; Published: 13 April 2018

\begin{abstract}
Premature battery drain, swelling and fires/explosions in lithium-ion batteries have caused wide-scale customer concerns, product recalls, and huge financial losses in a wide range of products including smartphones, laptops, e-cigarettes, hoverboards, cars, and commercial aircraft. Most of these problems are caused by defects which are difficult to detect using conventional nondestructive electrical methods and disassembly-based destructive analysis. This paper develops an effective computed tomography (CT)-based nondestructive approach to assess battery quality and identify manufacturing-induced defects and structural deformations in batteries. Several unique case studies from commercial e-cigarette and smartphone applications are presented to show where $\mathrm{CT}$ analysis methods work.
\end{abstract}

Keywords: lithium-ion battery; failure analysis; X-ray computed tomography; CT scan; battery defects

\section{Introduction}

Lithium-ion battery technology, first commercialized in 1991, has become popular for energy storage due to its higher energy density, higher voltage, and less required maintenance compared to other battery technologies. Lithium-ion batteries have six main components-two electrodes (an anode and a cathode), two current collectors, electrolyte, and a separator. The two electrodes-anode and cathode-are usually made of graphite and lithium metal oxide (e.g., $\mathrm{LiCoO}_{2}, \mathrm{LiMn}_{2} \mathrm{O}_{4}, \mathrm{LiNiMnCoO}_{2}$ ), respectively. These electrode materials are glued on the metallic current collectors. The anode and cathode current collectors are usually made of copper $(\mathrm{Cu})$ and aluminum $(\mathrm{Al})$, respectively. The two electrodes are electronically insulated from each other by a separator, which has been soaked in an organic electrolyte [1]. When the battery is discharged, the anode is oxidized, and lithium ions are deintercalated from the anode, travel through the electrolyte, and intercalate into the cathode. When the battery is charged, the cathode is oxidized, and the lithium ions move from the cathode to the anode.

Despite its many advantages, lithium-ion technology poses safety concerns due to the presence of the flammable electrolyte and oxidizing agents [2]. Battery internal defects due to poor manufacturing, such as low-quality separators, material contaminants, and improperly arranged constituents, 
can further aggravate the safety risks. Lithium-ion battery failure incidents, including premature battery drain, swelling, overheating, fires, and explosions, have been reported in almost every battery-powered system, ranging from smartphones and laptops, to e-cigarettes, hoverboards, electric cars, and commercial aircraft [3-6]. Samsung had to permanently halt the production of the Galaxy Note 7 in 2016 and order a wide-scale recall to address battery fire issues [7]. In 2017 there have been several reports of swollen lithium-ion batteries in MacBook Pro laptops [8]. Due to the growing number of incidents of e-cigarette battery fires, the U.S. Food and Drug Administration (FDA) hosted a science-based workshop in 2017, to gather information and stimulate discussion about e-cigarette battery safety concerns [9].

To assess batteries, destructive and nondestructive analysis methods are used at various points in a battery's lifetime to investigate battery failure causes. Destructive analysis involving battery disassembly enables a direct observation of the local microstructure and elemental compositions of each battery component [10]. A comprehensive review of the destructive techniques can be found in [11]. However, destructive methods are unacceptable for quality control assessment associated with battery fabrication and production because the battery cannot be used after analysis [12]; and disassembly of the battery can alter or destroy the original failure causes or battery defects.

Nondestructive analysis methods do not impede battery performance and can therefore be used for manufacturing quality control as well as to study the battery degradation during its operational life. Electrical testing methods, including capacity test [13], incremental capacity analysis (ICA) [14], and electrochemical impedance spectroscopy (EIS) [15], are the conventional nondestructive techniques to provide inferences for possible battery failure causes and mechanisms. Capacity test and ICA can be implemented in the battery management system (BMS) and provide direct indications for battery health state. The EIS method provides understanding of the evolution of physical processes inside batteries, which can help in identifying the failure mechanisms. However, these electrical testing methods require a working battery and careful consideration if the battery poses safety concerns.

There are other nondestructive failure detection methods which enable extracting failure precursors [16-19]. Sazhin et al. [16] showed that internal shorts could be assessed by measuring the self-discharge current. Jing et al. [17] proposed a rule-based method to detect the failure of over-discharged lithium-ion batteries by monitoring the temperature and voltage. However, all the nondestructive techniques listed above cannot detect localized design or material defects that lead to the failure, such as metallic protrusions, material contaminants, or non-uniform electrode layer structure.

Radiation-based imaging methods are increasingly being used to inspect batteries. These methods, including two-dimensional (2D) X-ray analysis, computed tomography (CT), and neutron radiography (N-ray), can reveal the interior of batteries nondestructively. Researchers have drawn special attention to CT for studying lithium-ion batteries because it provides three-dimensional (3D) images across multiple length scales. Thus, it is possible to visually inspect internal structural properties and quantitatively analyze material properties for lithium-ion batteries.

This paper provides a review of applications of CT scans in lithium-ion battery failure analysis and demonstrate, the application of CT scans for detecting manufacturing-induced defects and structural deformations in lithium-ion batteries. Section 2 provides an overview of CT scanning and discusses the parameters selection for lithium-ion battery research. Section 3 describes how CT scans can be used to investigate the causes and mechanisms of lithium-ion battery failure. Section 4 presents three case studies from e-cigarette and smartphone applications focusing on the defective batteries analysis. Section 5 provides conclusions.

\section{CT Scan Technology and Parameters}

CT scanning is a computer-aided tomographic process that uses $\mathrm{X}$-rays to produce $3 \mathrm{D}$ representations of the scanned object. As the X-rays pass through the object, they are attenuated due to absorption and scattering. The attenuation is measured by capturing the remaining $\mathrm{X}$-rays 
using a detector, forming a 2D gray image [20]. The 2D image provides only limited information for the internal structure of the object due to the superpositioned information of several materials. In contrast, $\mathrm{CT}$ scanning allows one to reconstruct the complete 3D volumetric model from a series of 2D projections acquired at different angles.

Figure 1 shows an industrial CT system with two principal components: an X-ray tube (source) and an X-ray detector. The entire object is projected on the detector from the X-ray tube. By rotating the tube (or the object) in small-angle steps, a series of $2 \mathrm{D}$ projections can be acquired. The $3 \mathrm{D}$ object is then reconstructed from these $2 \mathrm{D}$ images in the software.

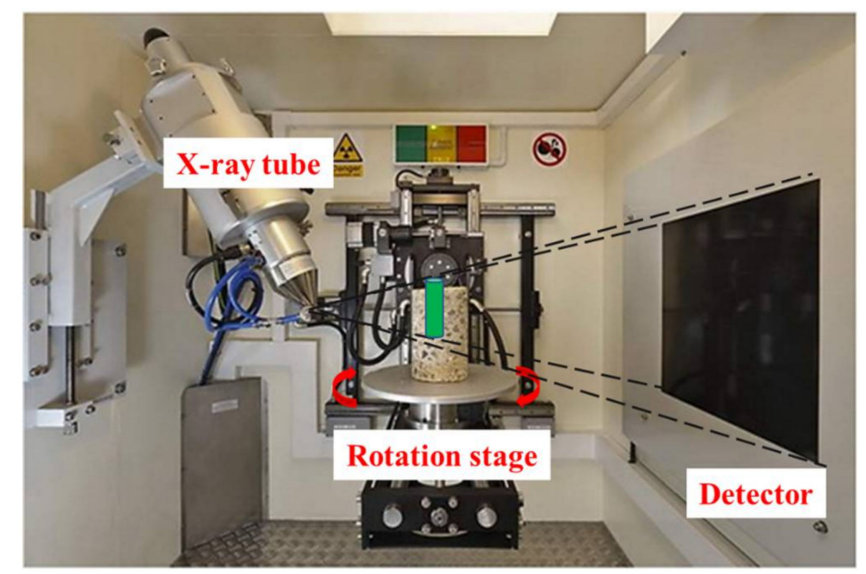

Figure 1. Example of an industrial computed tomography (CT) system.

As shown in Figure 2, a complete 3D object is composed of a contiguous set of CT images, called "slices" because they correspond to what the object would look like if it was opened along a plane. While a 2D image is made up of pixels, a CT slice is formed with voxels. The voxel is a 3D cube that represents the gray-scale value at that location. The gray-scale value corresponds to $\mathrm{X}$-ray attenuation, which reflects the proportion of X-rays absorbed or scattered as they pass through each voxel [21].

\section{D CT image}

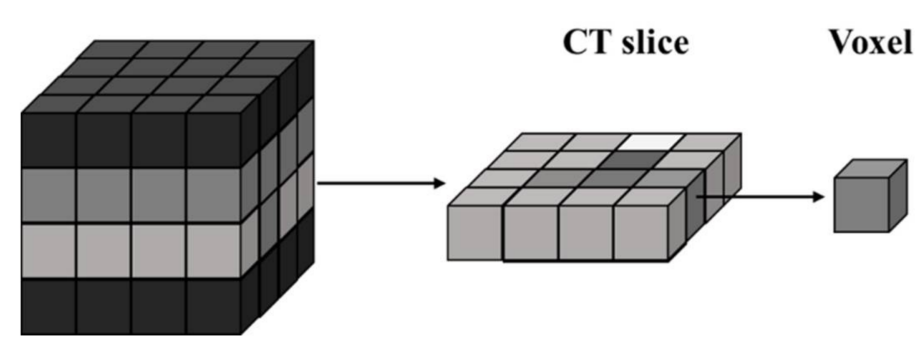

Figure 2. Construction of a 3D CT image.

Despite its powerful features, CT scanning still has some drawbacks. CT scanning is an expensive method that usually requires over an hour or more for a complete measurement compared with 2D X-ray scan which can take place in seconds. In addition, CT scanning involves complicated parameter set-up operations and requires a large amount of data storage and data analysis.

Figure 3 shows factors that influence the CT measurement [22]. The parameters that can be selected and controlled by the operator include: the target material, the power of the $\mathrm{X}$-ray source (source current, acceleration voltage), magnification, number of projections, and detector exposure time [23]. Selection and adjustment of the parameters may require test measurements and iterative procedures. 


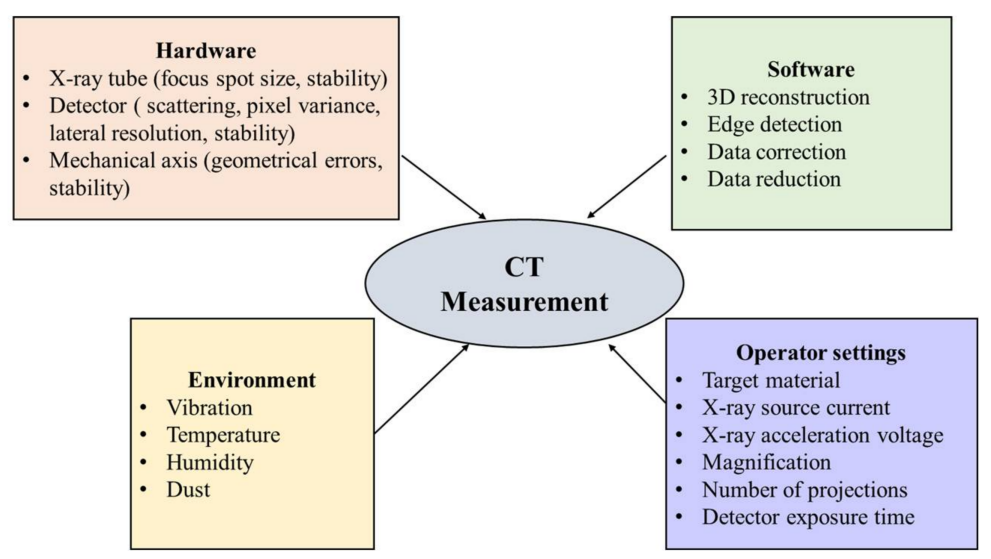

Figure 3. Influence factors for CT measurement.

\subsection{Target Material}

X-rays are produced by a metal object (target) hit by the accelerated electron beam in the X-ray tube. Thus, the target material influences the shape of the $X$-ray spectrum. This spectrum is determined by both the X-ray intensity and X-ray energy levels [24]. A high X-ray intensity and energy level indicates a high penetration ability. When a target material with high atomic number is selected, it will cause a shifting of the X-ray spectrum towards both high X-ray intensity and energy level (see Figure 4) [25]. That is why tungsten is usually chosen as the target material for scanning batteries in comparison with other target materials, such as copper, aluminum, and molybdenum. Because tungsten has a higher atomic number (74) than the others, it can create the X-ray spectrum with sufficient penetration ability through the batteries. Besides, it has a high melting point $\left(6192{ }^{\circ} \mathrm{F}\right)$, which is suitable for operation under high $\mathrm{X}$-ray current.

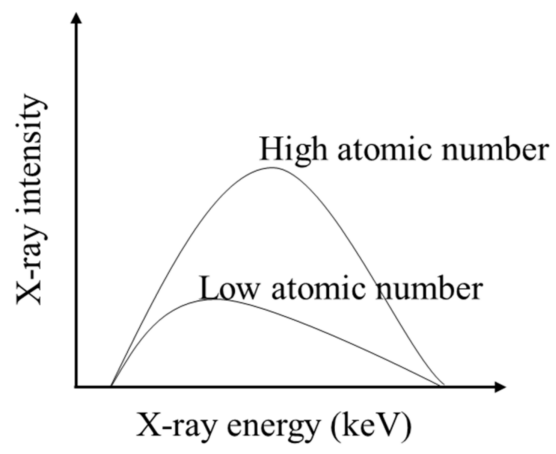

Figure 4. Influence of atomic number of the target material on the X-ray spectrum.

\subsection{X-ray Power (X-ray current and voltage)}

The power of an X-ray beam is characterized by the X-ray voltage and current applied to the electron beam that hits the target. The voltage determines the maximum X-ray energy and the penetration power. The attenuation of the X-ray with initial intensity $I_{0}$ passing through the battery can be described by Lambert-Beer's law [26]:

$$
I=I_{0} e^{-\mu x}
$$

where $x$ is the length traveled within the battery and $\mu$ is the attenuation coefficient, which is determined by the density and atomic number of the battery materials and the X-ray energy (i.e., the voltage). 
In a CT scan, the transmission value $\left(I / I_{0}\right)$ determines the contrast in a CT image. For lithium-ion batteries, the transmission value of around $30 \%$ has been recommended in the existing research [27]. This desired transmission value $\left(I / I_{0}\right)$ can be obtained by choosing a proper X-ray voltage range because $\mu$ in Equation (1) is dependent on the X-ray voltage. The US National Institute of Standards and Technology (NIST) has provided X-ray attenuation coefficients $(\mu)$ for elements with atomic number from 1 to 92 under different $X$-ray voltages. The list of attenuation coefficients can further help choose the suitable $\mathrm{X}$-ray voltage values corresponding to a certain transmission value, battery property, and geometry [28].

In addition to X-ray voltage, the source current should be set before scanning. The level of the current is related to the radiation dose (proportional to both the source current and the detector exposure time) [29]. The amount of the radiation dose will affect not only material property but also the quality of CT image. The existing study has verified that the amount of the radiation dose can cause material degradation [30]. However, this understanding has not been further validated in the stability of electrode materials of lithium-ion batteries. Additionally, a high radiation dose can increase the signal-to-noise ratio (SNR) of a CT image [24]. SNR is the ratio of the level of the desired image signal to the image noise. Ideally, the image signal depends on the mean value of the numbers of detected photons and the image noise is the degree of measurement uncertainty, which can be presented by the standard deviation of the numbers of photons. Increasing the source current can increase the number of detected photons and thus increase the SNR. Therefore, the X-ray current should be selected by balancing the quality of the $\mathrm{CT}$ image and the radiation dose.

\subsection{Magnification}

The resolution of a CT scanner is usually represented as the voxel size (vs). The voxel size is determined by the magnification $(M)$ and the pixel-to-pixel distance of the detector (dis). As shown in Figure 5, the magnification is defined as the ratio of the source-to-detector distance over the source-to-sample distance [31]:

$$
M=F D D / F O D
$$

where $F O D$ is the distance between the $\mathrm{X}$-ray source and the battery and FDD is the distance between the $\mathrm{X}$-ray source and detector.

Larger magnification is achieved by moving the sample closer to the focus. The entire sample must remain within the field of view (FOV) of the detector. Thus, the maximum $M$ is determined by the ratio of the maximum detector width $(D)$ and the battery width $(d)$ :

$$
M_{\max }=D / d
$$

Voxel size can be calculated by the pixel-to-pixel distance of the detector and the magnification:

$$
v s=d i s / M
$$

The thickness of the electrode layers in the commercial lithium-ion batteries is about $100 \mu \mathrm{m}$. Thus, a resolution on the order of less than $100 \mu \mathrm{m}$ is required to distinguish the adjacent layers for lithium-ion batteries.

At the same time, in order to get an enlarged image for the entire battery, the size of the battery must be smaller than the detector. Standard commercial detectors usually have $2048 \times 2048$ pixels with a pixel size of $200 \mu \mathrm{m}$. This size is larger than that of a commercial 18650 cylindrical cell. 


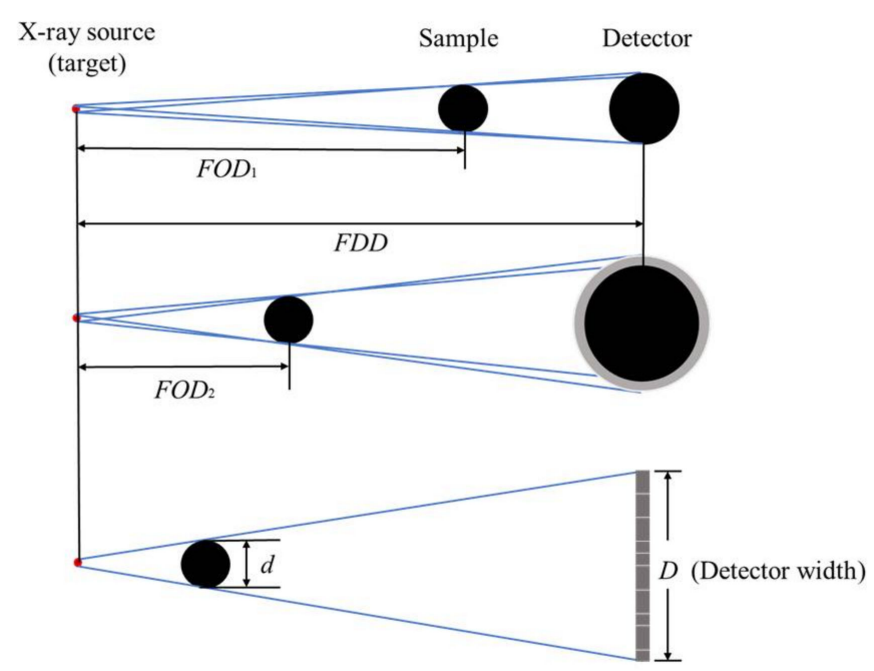

Figure 5. Image magnification for CT scanning.

\subsection{Number of Projections}

The number of projections (angle positions) is directly associated with scanning time. Users in industry try to reduce the number of projections to reduce the scanning time. However, decreasing the number of projections will reduce the image quality. A small number of projections (i.e., a large angle between two adjacent projections) can lead to misregistration of information for the small objects and sharp edges. This issue can cause an artifact called "view aliasing" [32]. A rule of thumb is that the number of projections should be the same as the diameter of the sample in units of pixels multiplied by $\pi / 2$. For example, assume a detector has a width of 2000 pixels, then, the sample with a maximum diameter of 2000 pixels can fit in the FOV of the detector. A $180^{\circ}$ acquisition of the sample has a total of $\pi \times 2000 / 2 \approx 3140$ pixels. Thus, collecting 3140 projections can lead to 1 -pixel change in each projection [27]. This number of projections is enough to reconstruct adequate CT images.

\subsection{Detector Exposure Time}

The total time for performing a CT scan is determined by the available X-ray energy, number of projections, detector exposure time, and data processing algorithms [33]. The detector exposure time is the amount of time required to image each projection of a CT scan. Similar to the X-ray current, exposure time will also affect the image quality. Increasing the exposure time can increase the number of detected photons and then increase the SNR. However, it will also cause an increase in the total scanning time. Therefore, selection of the exposure time should take into account the acceptable testing time and the required the image quality.

\section{Applications of CT Scanning for Lithium-Ion Battery Analysis}

The 3D CT images enable researchers to gain insight into a battery's internal structure as well as material composition through visualization and quantification of the images. CT scan also enables one to identify the possible failure causes of a failed battery.

The pouch and cylindrical formats are the most widely used batteries for cellphones, laptops, and high-energy/high-power applications such as electric vehicles. Cylindrical batteries usually have firm steel casing to protect battery components from external mechanical stresses. Under extreme conditions such as rapid gas generation, pressure build-up can occur, leading to violent venting or even explosion. Pouch batteries are usually sealed with Al foil. They can be easily damaged due to the lack of structural support [34].

Cylindrical batteries are manufactured by winding the cathode and the anode layer separated by a separator into a jelly roll. The cathode current collector is connected with the cap (positive 
terminal) using the positive tab (typically Al). The anode current collector is connected with the outer casing (negative terminal) using the negative tab (typically $\mathrm{Ni}$ ), which is isolated from the cap by an insulating ring. Figure $6 a, b$ show the axial and front $C T$ scan images of a cylindrical lithium-ion battery. The X-ray attenuation and the gray-scale value typically increase as the atomic number of the element increases [35]. The anode current collector $(\mathrm{Cu})$ and negative tab $(\mathrm{Ni})$ have higher atomic numbers than the cathode current collector ( $\mathrm{Al}$ ) and anode material (C). Thus, the elements with high atomic numbers, such as the anode current collector $(\mathrm{Cu})$, have high $\mathrm{X}$-ray attenuations and gray-scale values and are displayed as white in the CT images. While the elements with low atomic numbers, such as the anode material (C), have low gray-scale values and are shown as black.

Figure $6 c, d$ show the gray-scale values along the green dashed lines in Figure $6 a, b$, respectively. The outer casing (left and right peaks in Figure $6 c, d$ ) is made of steel and has similar gray-scale values as the negative tab (Ni). Because the atomic number of $\mathrm{Al}(13)$ is smaller than $\mathrm{Ni}(28)$, the positive tab (Al) shows lower gray-scale value compared with the negative tab (Ni). The jelly roll, including both elements with high atomic numbers $(\mathrm{Cu}, \mathrm{Co}, \mathrm{Ni}, \mathrm{Mn})$ and elements with low atomic numbers $(\mathrm{Li}, \mathrm{Al}$, $\mathrm{C}, \mathrm{O}$ ), is shown as a scatter within a gray-scale range between the positive and negative tabs.

After determining the positions of the positive and negative tabs, the distribution of the cathode and anode current collectors can be obtained because they are connected with the corresponding tabs. Then, the layers on both sides of the cathode current collector are identified as the cathode layers. And the anode layers are on both sides of the anode current collector. Figure 7 shows a CT scan image of a cross-section of the electrode layers, and each layer is marked in the image.
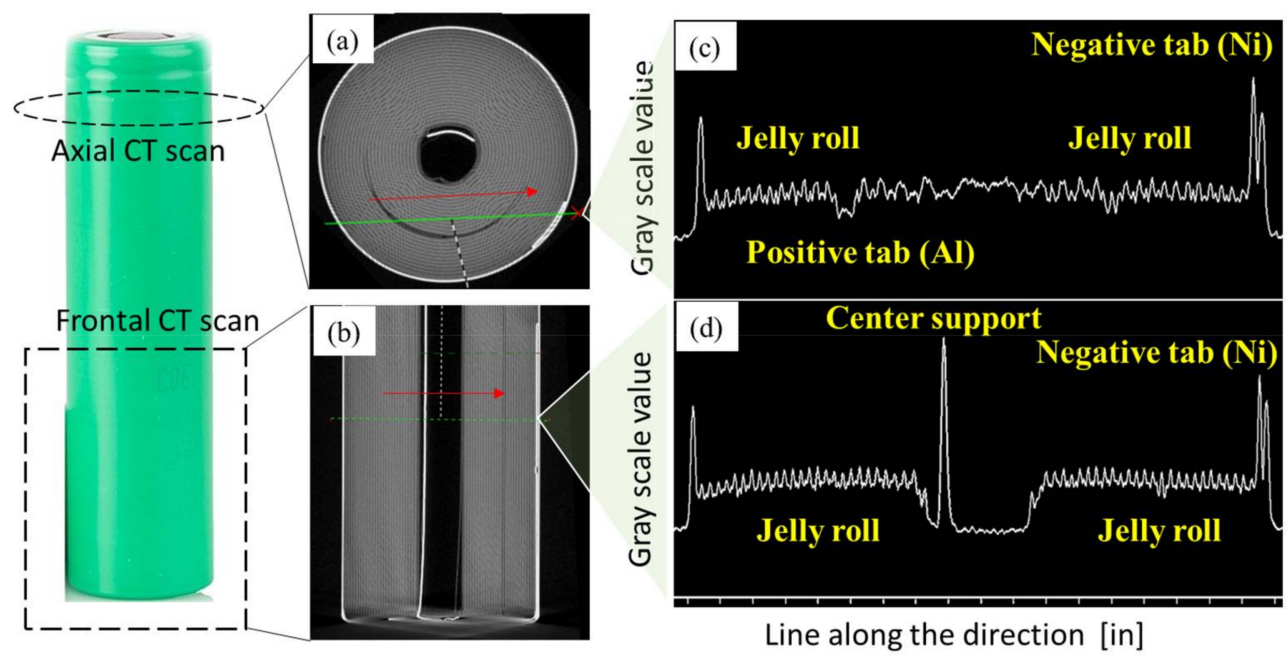

Figure 6. CT scan images of a cylindrical lithium-ion battery: (a) axial view; (b) front view; (c) gray-scale values for the line in the axial view; (d) gray-scale values for the line in the front view. 


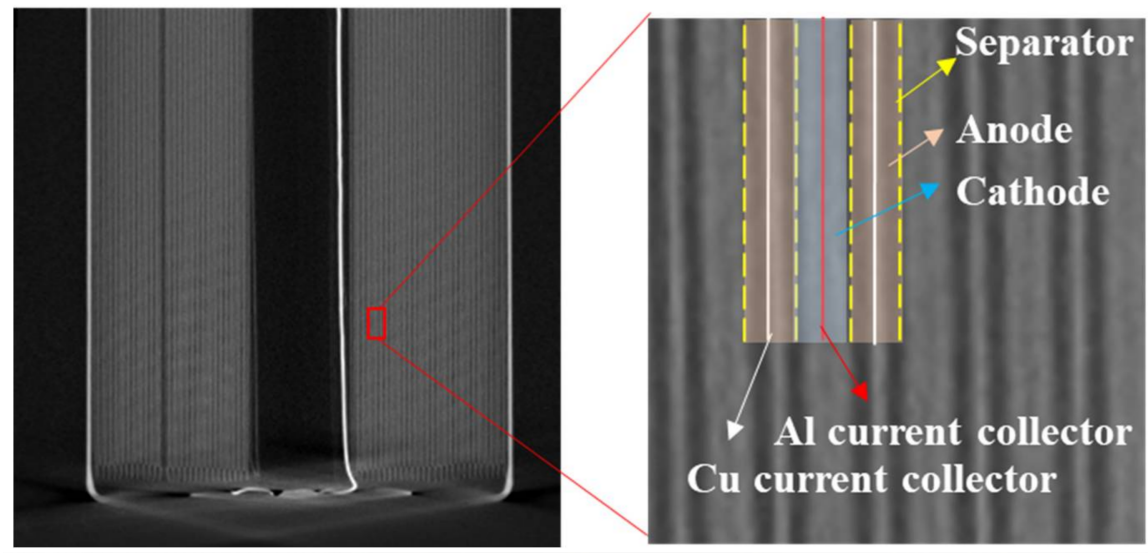

Figure 7. CT image of the cross-section of the electrode layers for a lithium-ion battery.

Figure 8 shows the magnified CT images for the top and front views of the lithium-ion battery. According to the CT images, a good battery does not have jelly roll deformation, burrs on the electrode tabs, electrode misalignment, or material contaminants (foreign materials).

Several papers have reported the use of CT scanning to assess structural changes in lithium-ion batteries due to various failure mechanisms [36,37]. Electrode deformation in the cycled lithium-ion batteries has been detected using CT scanning. Waldmann et al. [38] observed deformation of the jelly roll in cylindrical batteries without a center pin after cycling at both low (1C discharge) and high C-rate (16C discharge). Yufit et al. [39] showed that there was an increase in the separation between two adjacent electrodes for the failed pouch cell after 14 cycles as compared to the fresh cell. Zhang et al. [40] observed a wave-like deformation in the electrodes of a pouch cell, cycled for 2000 times at $0.5 \mathrm{C}$, using CT scan images. They proposed that the deformation was induced by the microscopic lattice expansion of the anode.
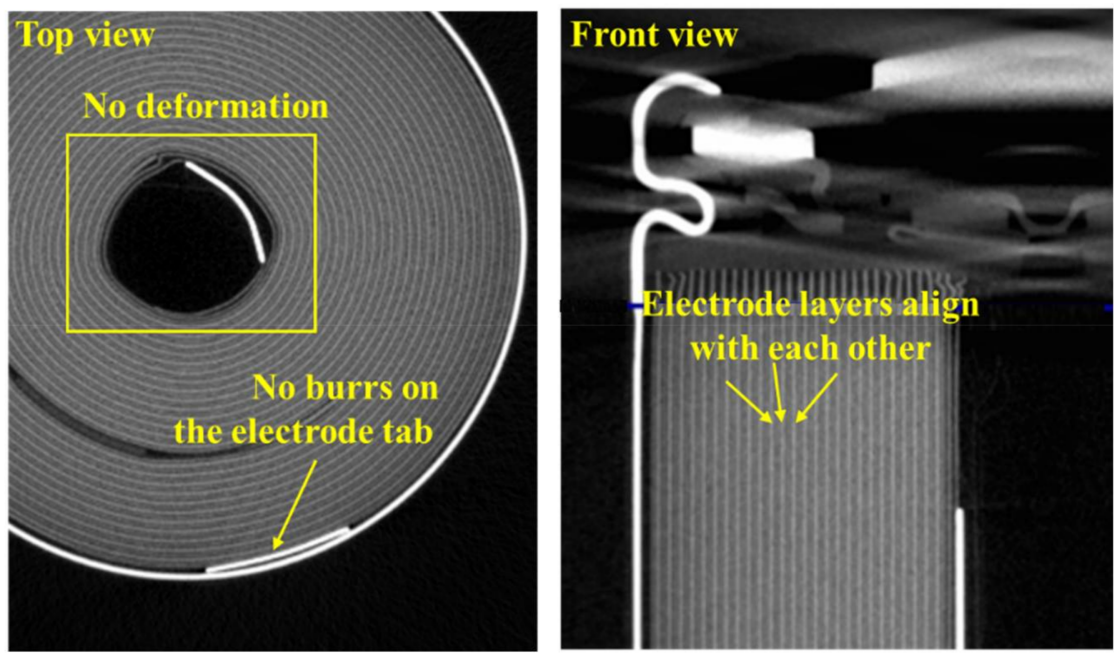

Figure 8. Magnified CT scan images of a cylindrical lithium-ion battery.

Finegan et al. [41] performed CT scans to track the evolution of structural damage associated with thermal runaway of commercial 18650 batteries during external thermal abuse. The separation of the electrode layers was observed to stem from the separator region due to melting of the separator and gas generation from SEI breakdown and electrolyte reduction. The failure mechanisms leading up to overcharge-induced thermal runaway of a $\mathrm{LiCoO}_{2}$ pouch cell were also explored by Finegan et al. [42]. $\mathrm{CT}$ images revealed delamination of the cathode materials from the current collectors in various places, 
which provided evidence for the cathode decomposition. Bond et al. [43] demonstrated the use of synchrotron-based CT for characterizing the changes in the electrode geometry in a prismatic cell during overdischarge-induced gas evolution. CT images showed that parts of the electrodes were deformed prior to abuse and most of the changes occurred in those deformed areas after overdischarge.

One example of using CT scanning for defects analysis is the Samsung Galaxy Note 7 smartphone. This smartphone was in the news in 2016 because of fire incidents [7]. According to the CT scan analysis, the pouch batteries from the manufacturer did not have sufficient space between the edge of the electrodes and the cell case at the corner area. This kind of design can cause electrode deflection at this area and induce high current density, which can lead to local lithium plating. Also, because of the deflected electrode layers, the separators between these layers can be stretched and get thinner than the original situation. Based on this finding, Samsung concluded that the plated lithium can lead to cell short circuit by penetrating the separator $[44,45]$. In another case, the pouch batteries had welding burrs on the positive tab. The burrs possibly penetrated the insulation tape and the separator, causing a short circuit between the positive tab and the $\mathrm{Cu}$ current collector.

\section{Case Studies}

Additional applications of CT scanning for lithium-ion battery defects analysis are discussed below with the help of three case studies on lithium-ion batteries from different applications. The first two types of cells (i.e., 18650 cylindrical cells and pouch cells) are associated with two e-cigarette explosion incidents that occurred in 2016 and 2017. The pouch cells in the third case are associated with battery drain issues in smartphones. Both the failed and fresh cells were used to identify the internal defects in those cases.

An XTEK XT H 320 LC instrument (Nikon Metrology Inc., Shinagawa, Tokyo, Japan) was used to conduct the CT scan experiment. Tungsten was chosen as the target material. Table 1 summarizes the CT operation parameters. CT scanning for each battery took about $1 \mathrm{~h}$. The volumetric CT datasets were reconstructed with standard filtered back-projection algorithms. The datasets were analyzed using the myVGL software (Version 3.1, Volume Graphics GmbH, Heidelberg, Germany).

There are several kinds of defects that can be introduced during the battery manufacturing process, which can be generally classified into structural deformations, such as electrode misalignment and burrs on the tabs; and material defects, such as metallic contaminants. The structural deformations can be detected through direct observation of the CT images from different angles. For the material defects, gray-scale analysis can be conducted to identify the foreign materials which have different compositions from the jelly roll.

Table 1. Parameter settings for the computed tomography (CT) scanner.

\begin{tabular}{cc}
\hline Parameters & Values \\
\hline Source current & $111 \mu \mathrm{A}$ \\
Acceleration voltage & $180 \mathrm{kV}$ \\
Voxel size & $28-30 \mu \mathrm{m}$ \\
Number of projections & $1700-1900$ \\
Detector exposure time & $1000 \mathrm{~ms}$ \\
\hline
\end{tabular}

\subsection{E-Cigarette with a Replaceable Battery}

E-cigarettes are battery-powered devices that vaporize a liquid solution to deliver a dose of nicotine to the user through oral inhalation [46]. They have become popular as an alternative to traditional tobacco products. Three main components comprise an e-cigarette: the cartridge or tank, the atomizer (the heating element), and the battery (power source). Lithium-ion batteries are the main technology used in battery-based e-cigarettes due to their high energy density and high voltage levels. With the spread of e-cigarette usage, numerous e-cigarette-related fire and explosion incidents have come to surface. In particular, from August 2009 to January 2017, there have been more than 
200 e-cigarette explosions reported worldwide, with nearly 100 incidents in 2016 alone [47]. Defective and substandard lithium-ion batteries are considered to be the main causes for these incidents.

On 10 January 2017, an e-cigarette exploded in a user's pants pocket. Two samples in Figure 9 are related to this incident. A1 is the subject battery that exploded in this incident while A2 is a backup battery of identical make and model. These two samples are rechargeable cylindrical 18650 cells with 3000 mAh nominal capacity.

Since A1 had exploded, it was unsafe and impossible to conduct electrical testing to investigate the failure causes and mechanisms of this battery. However, CT scanning could be conducted for A1. Figure 10 shows the top, right, and front views, and a 3D image of the CT scan of A1. As shown in the CT image, the shape of the internal structural support remained almost unchanged while the casing and the electrode layers were severely deformed. Some bright particles (high X-ray attenuation) were observed within the battery. These particles are likely $\mathrm{Cu}$ because their brightness is similar to that of the $\mathrm{Cu}$ current collector [41].

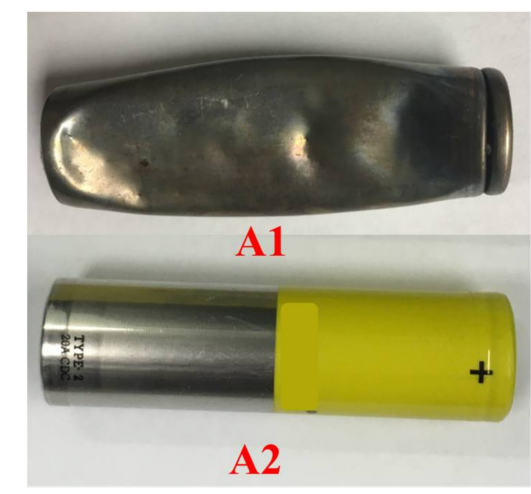

Figure 9. Photo of the exploded (A1) and backup (A2) e-cigarette cylindrical 18650 cells.

Figure 11 shows the area of interest of the sample A1. The gray-scale values of the bright particles were examined. The particles have higher gray-scale values compared with the jelly roll. This means they have the different composition from the electrode materials. These particles may come from either the anode current collector $(\mathrm{Cu})$ or the negative tab $(\mathrm{Ni})$ or both of them.

In addition to the bright particles, welding burrs on the negative tab can be seen in Figure 11. The negative tab is usually placed starting from the middle region of the battery body to the bottom of the battery. To investigate the effect of the defective negative tab on the collapse of the internal structure, a comparison of the axial views with and without the negative tab are shown in Figure 12. The axial view 1 without the negative tab is from the upper part of the sample. This image indicates that most of the electrode layers retained their original form in this area. The axial view 2 with the defective negative tab is from the lower part of the sample. In contrast to the axial view 1 , almost half of the electrode layers were destroyed in this area. This indicates that local heat may be generated near the defective negative tab at the lower part of this sample. A hypothesis is that the increase in the internal temperature accelerated the side reactions such as decomposition of the electrode materials. These side reactions further produced a large amount of heat and finally induced thermal runaway. 


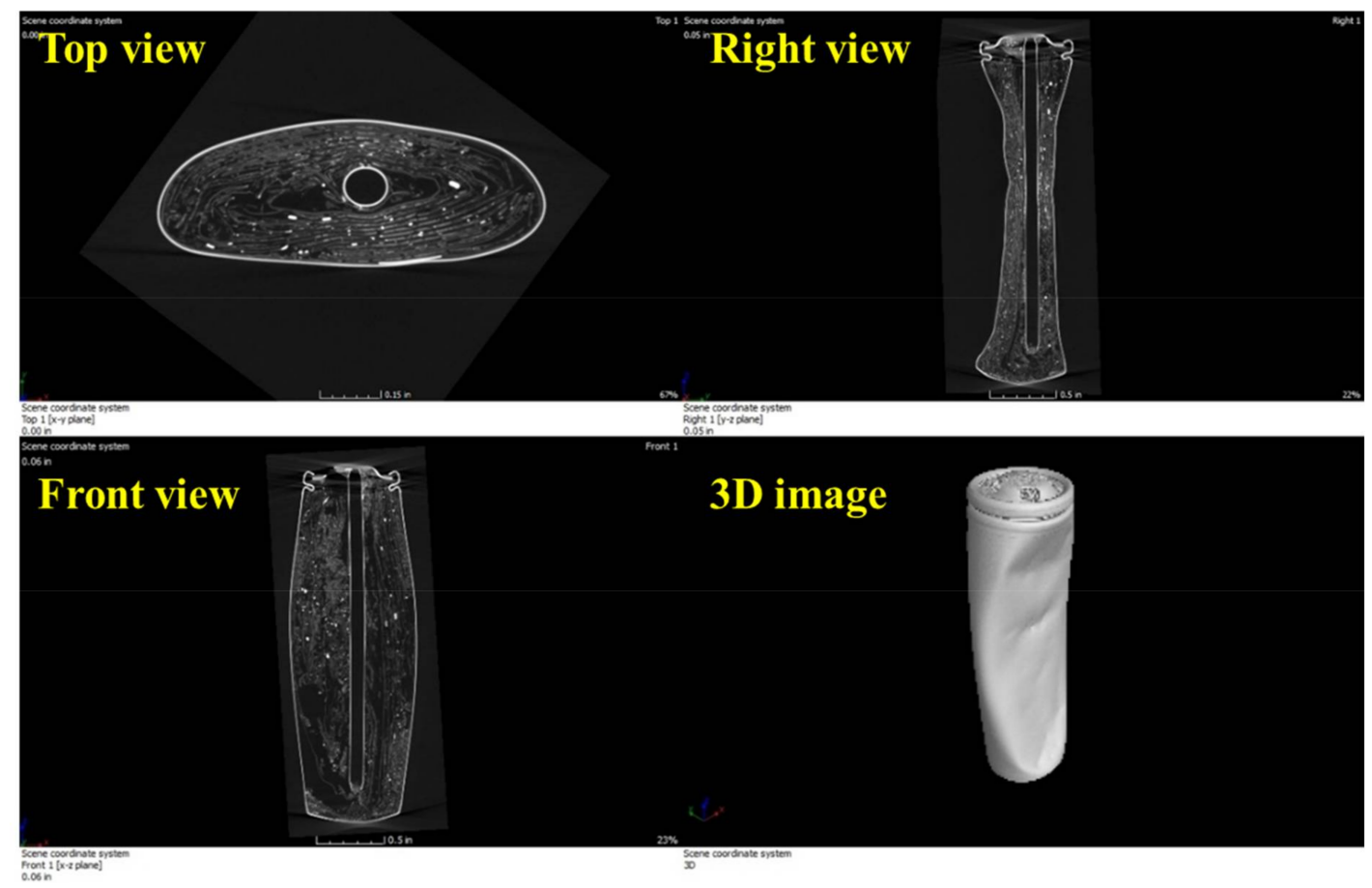

Figure 10. CT scan of the sample A1.
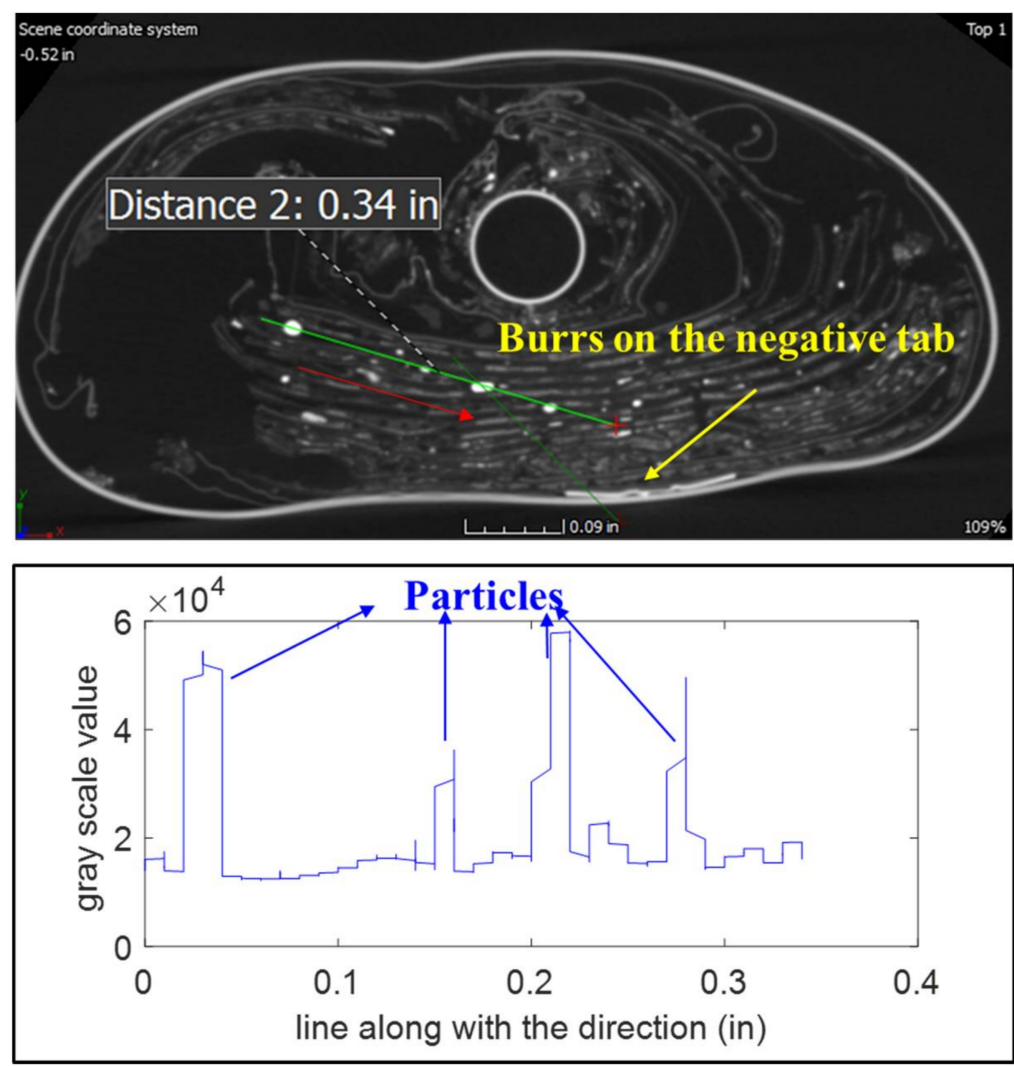

Figure 11. Area of interest of the sample A1 and the gray-scale profile along the marked green line. 


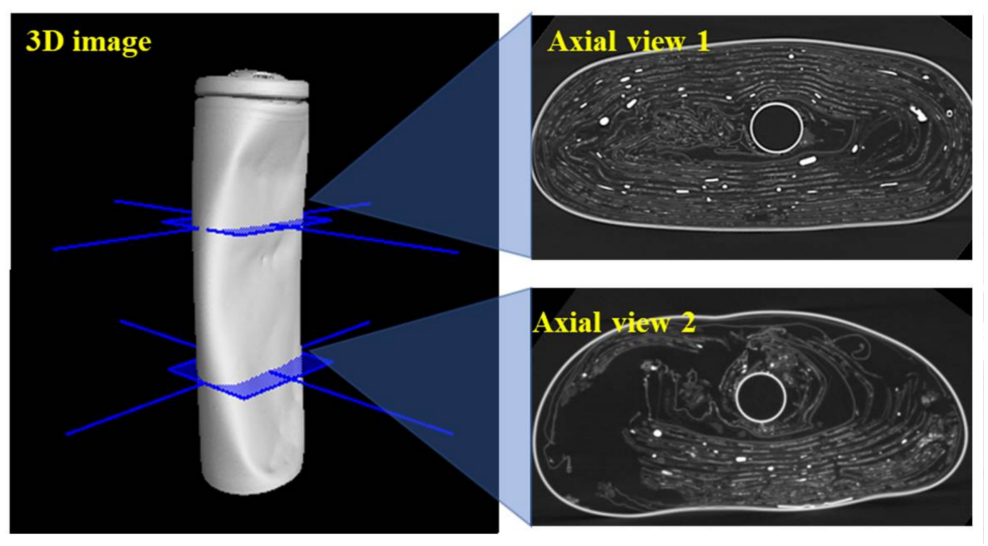

Figure 12. Axial views with and without the negative tab of the sample A1.

To identify the failure causes of the exploded battery, the backup battery A2 was also examined by CT scanning. Figure 13 shows the top, right, and front views, and a 3D image of the CT scan of the sample A2. Figure 14 shows the CT scan near the positive and negative terminals of A2. The electrodes appear to be uniformly arranged, and there are no signs of structural deformation and electrode deflection. Figure 15 shows an enlarged section of the battery near the negative tab from different views. Welding burrs are observed on the negative tab for A2. The welding joints show sharp edges, which can lead to the puncture of the separator and electrical contact between the negative tab and positive electrode.

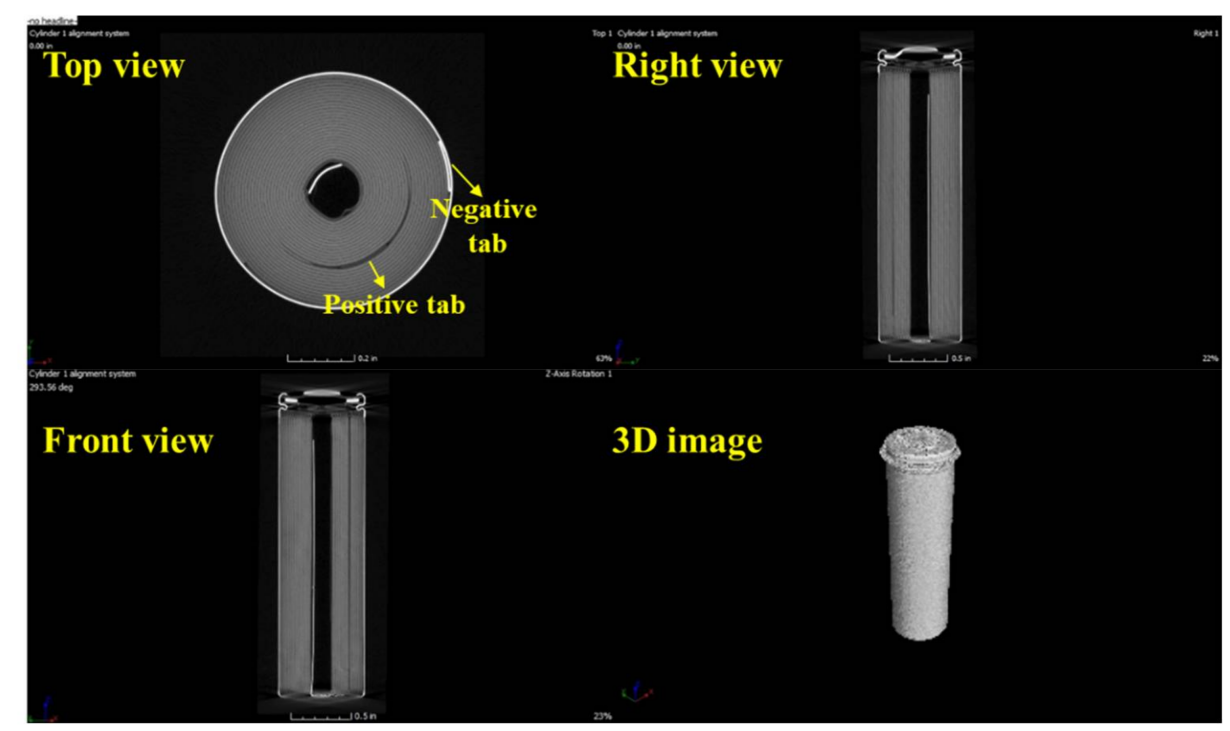

Figure 13. CT scan of the sample A2. 


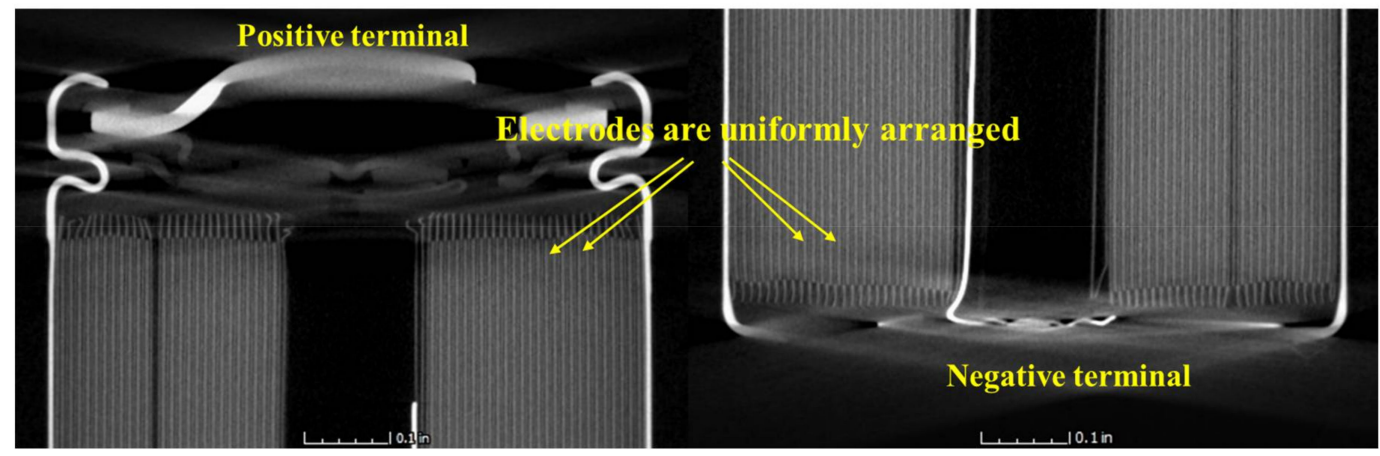

Figure 14. CT scan images near the positive and negative terminals of the sample A2.

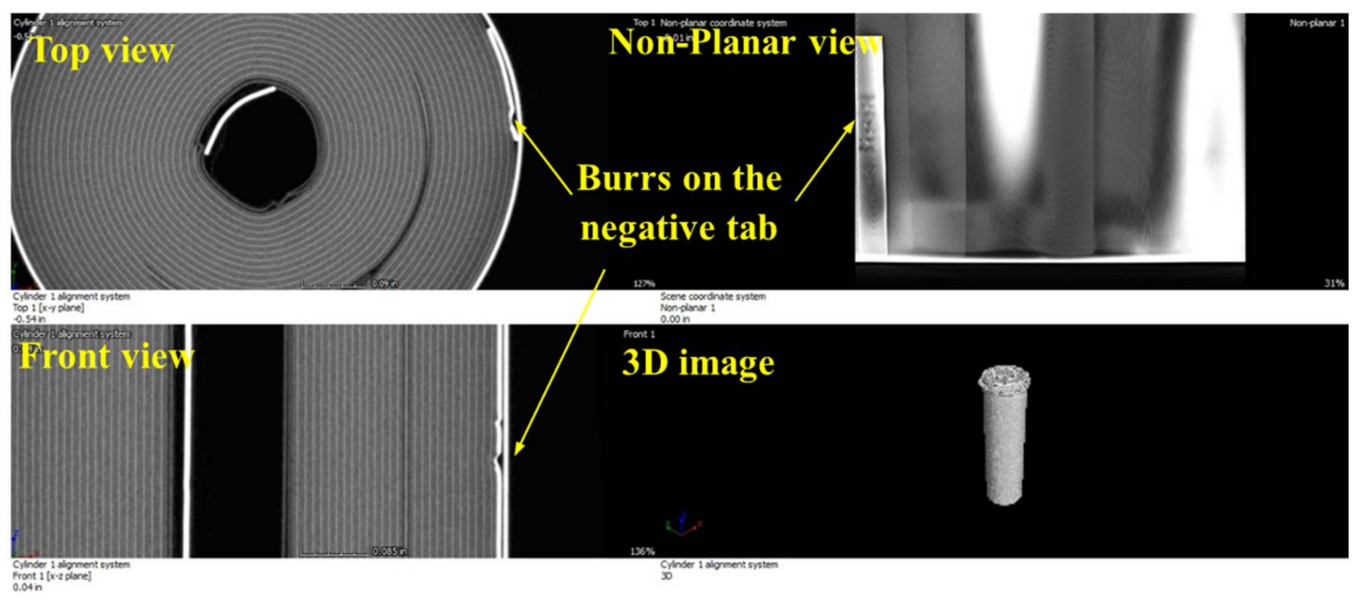

Figure 15. CT scan images near the negative tab of the sample A2.

The welding burrs were observed in both the exploded sample A1 and the backup sample A2. During battery charge/discharge, the normal contraction and swelling of the electrodes can force the welding burrs into the opposing positive electrode and thus through the separator, causing the two electrode layers to touch each other. An internal short circuit then occurs and results in overheating and in some cases thermal runaway of the battery.

\subsection{E-Cigarette with a Built-In Battery}

On 29 November 2016, an e-cigarette exploded when the user was pulling the e-cigarette from the charger after charging for $1 \mathrm{~h}$. Since the e-cigarette was totally burned, it cannot be used for further investigation. Hence, two new e-cigarettes of identical make and model were analyzed. Figure 16 shows samples taken from these e-cigarettes. Sample B1 is an e-cigarette battery holder with a built-in cell inside. Sample B2 is a built-in cell taken out of the other e-cigarette battery holder. The exposed wires at the cell terminals were wrapped with electric tape to avoid short circuit. Both B1 and B2 were examined using CT scanning.

Foreign particles were observed in different places inside the sample B1. Figure 17 shows a bright point inside B1 from different views. Figure 18 shows the gray-scale values of the marked green line crossing this point. The bright point shows a peak value which is different from the jelly roll. This means the point is another material that is not from any layers of the battery. The gray-scale value for this particle is larger than the positive tab $(\mathrm{Al})$ and smaller than the negative tab $(\mathrm{Ni})$, which means the particle's atomic number may be higher than $\mathrm{Al}$ and less than $\mathrm{Ni}$.

The foreign particles can be introduced during the coating and assembly process. Particle contaminations can exist in the slurries of the active materials that are used to coat the electrodes. If the 
assembly environment is not well controlled, the blades and other tools used in the assembly process can leave burrs and particles in the raw materials. Also, the weld splatter from the current collector tabs or nickel plating on the casing can be introduced. These foreign particles can lead to battery failures in multiple ways. Firstly, during charging/discharging, the battery undergoes thermo-mechanical stress due to contraction/expansion of the electrodes, and the foreign particles may puncture the separator and result in a short circuit. Secondly, some particles may be smaller than the pore size of the separator and directly diffuse through the pores and create a short circuit inside the battery. In addition, some metallic foreign particles may participate in the electrochemical reactions and form metallic alloys that hinder the lithiation process and are prone to be the spots for lithium plating, which can eventually result in a short circuit [48].

In the CT scan of B2 we also observed deflected anodes (see Figure 19), which are not desired during the fabrication process. Theoretically, there has to be a separator layer between the deflected anode and the cathode to avoid direct contact between these two electrode layers. However, the separator was invisible in the CT images because of its low attenuation. Due to the deformation in the deflected area, the anode materials can be stripped from the current collector and cause locally high current density. Such high current density can induce lithium plating on the anode and finally lead to an internal short circuit. Additionally, the non-uniform cathode layers were observed, which can be caused by the poor electrode coating process. This non-uniformity can lead to uneven current and temperature distributions inside the battery and cause accelerated degradation of the battery performance.

Another observation from the CT scan was that the location of the electrode tabs (Figure 20) showed the poor quality control during the manufacturing process. The electrode tabs usually have higher temperature than the jelly roll due to current concentration. So it is desirable to place the positive and negative tabs at different radiuses and different sides of the jelly roll (see Figure 13) to improve the heat dissipation. However, the electrode tabs were rolled on the same side in B1. This kind of tab design can cause high temperature near the tab region, which can lead to decomposition and stripping of the electrode materials. In addition, the tabs in B2 were overlapped with each other. These tabs are usually electronically insulated from each other by the insulating tapes. However, the high temperature in the overlapped area can lead to melting of the insulation tapes, which can result in a short circuit between these two tabs.

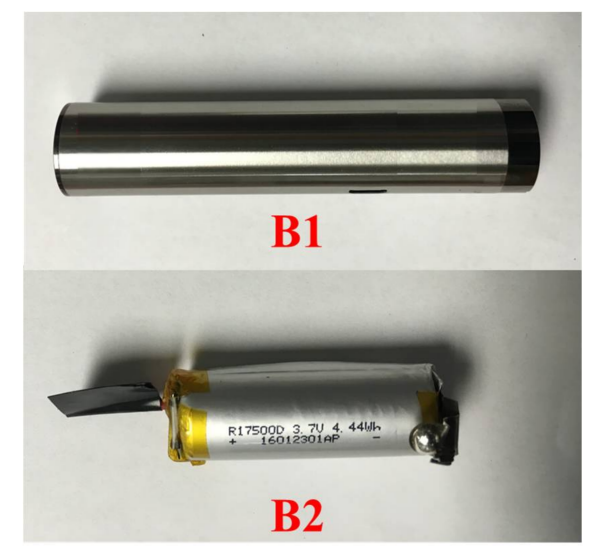

Figure 16. Photo of the e-cigarette battery holder (B1) and the built-in cell (B2). 


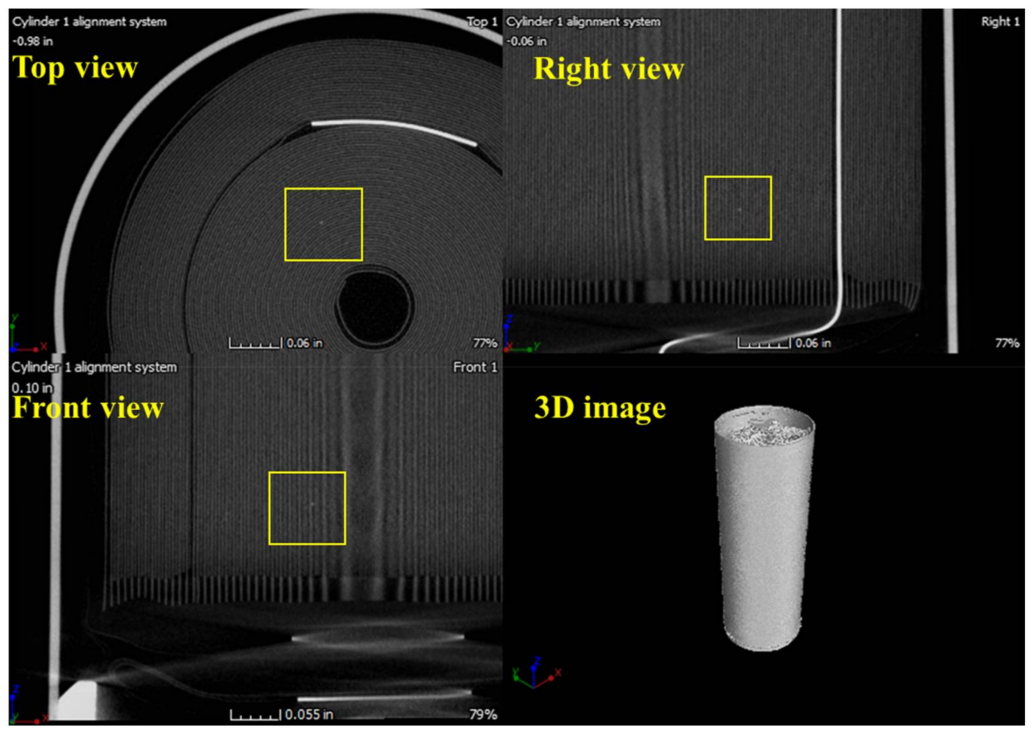

Figure 17. CT scan of the sample B1.

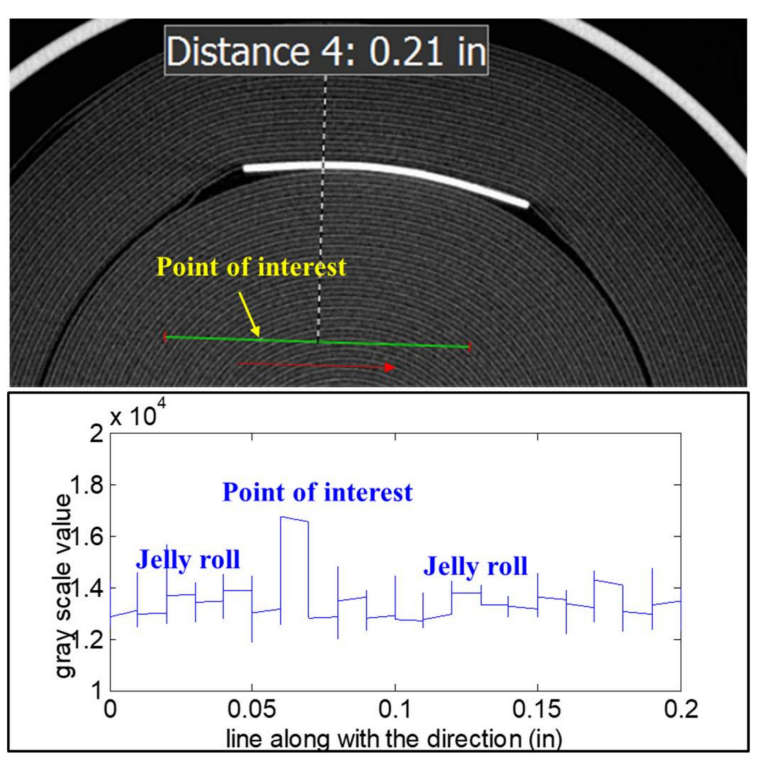

Figure 18. Point of interest of the sample B1 and the gray-scale profile along the marked green line.
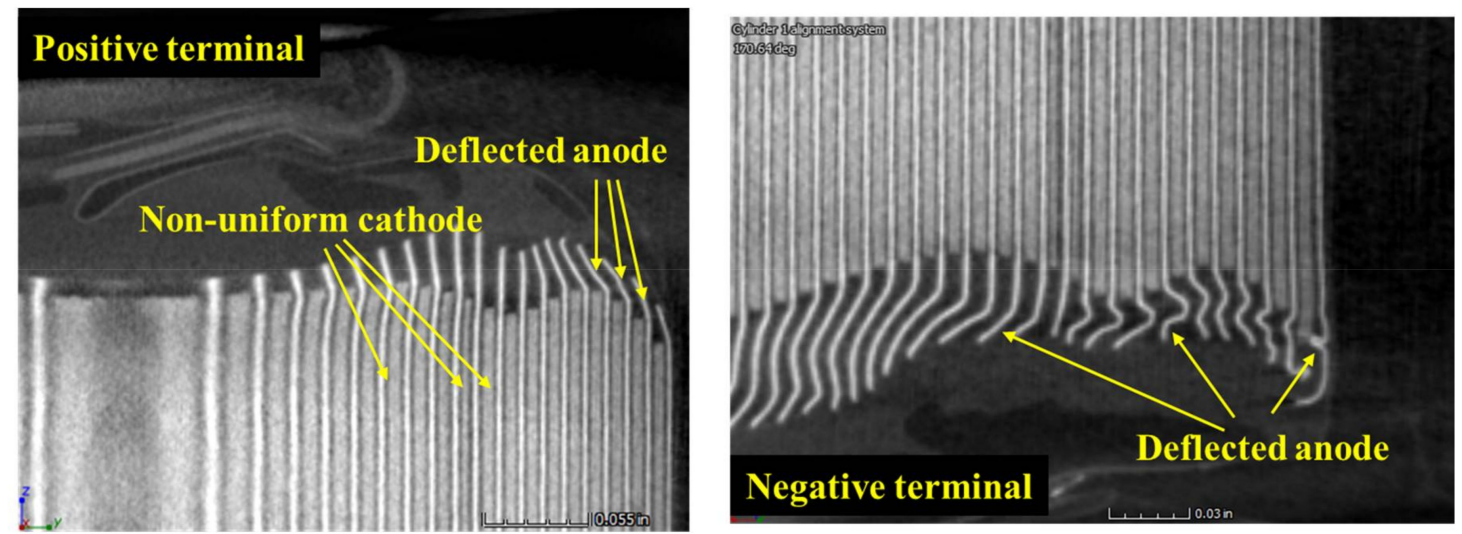

Figure 19. CT scan images near the positive and negative terminals of the sample B2. 

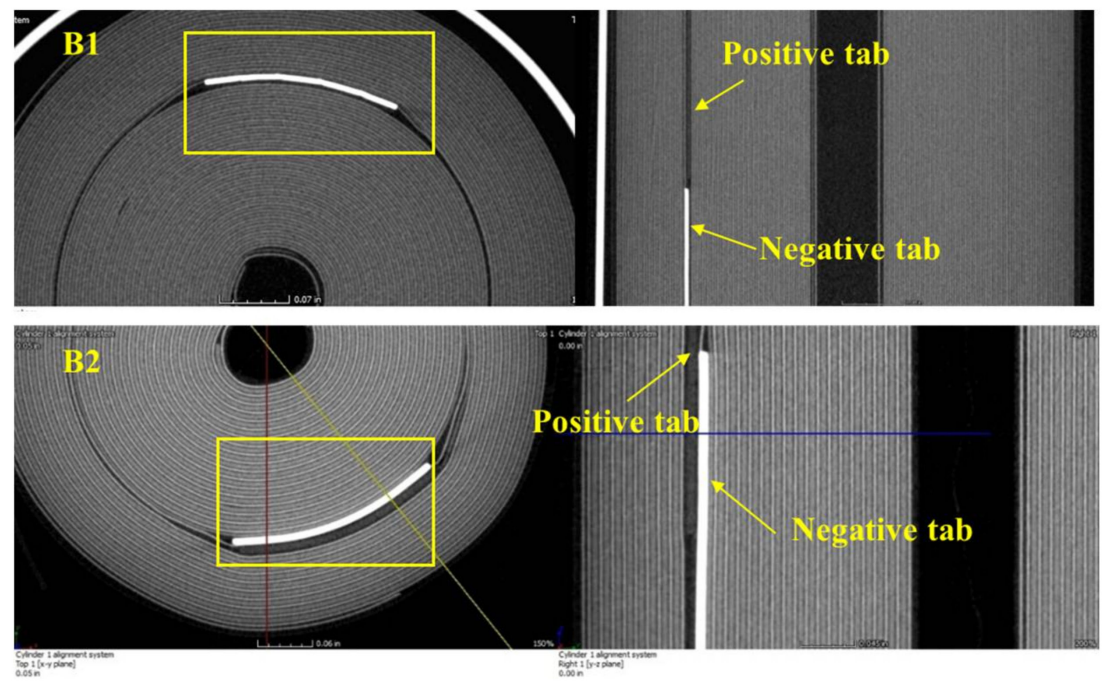

Figure 20. Electrode tabs of the samples B1 and B2.

\subsection{Smartphone}

There have been numerous reports of battery drain issues in Android-based smartphones, causing premature shutdown even when there appears to be significant battery runtime remaining $[49,50]$. A CT scan analysis was conducted on the $3450 \mathrm{mAh}$ rated lithium-ion batteries in one used and one new smartphone to investigate manufacturing quality and internal defects.

In Figure 21, CT scan images reveal the internal structure of the lithium-ion battery from the used smartphone. A significant amount of non-uniformity in the placement of the electrode layers of this cell can be observed.

Figure 22 shows a bright particle inside the used sample. The particle has a higher gray-scale value compared with the jelly roll, which indicates that it has material composition different than the material of the nearby jelly roll. Similar types of particles were observed in other parts of the battery. This kind of foreign particle can cause battery internal short circuits as discussed for sample B1 in the second e-cigarette case. 

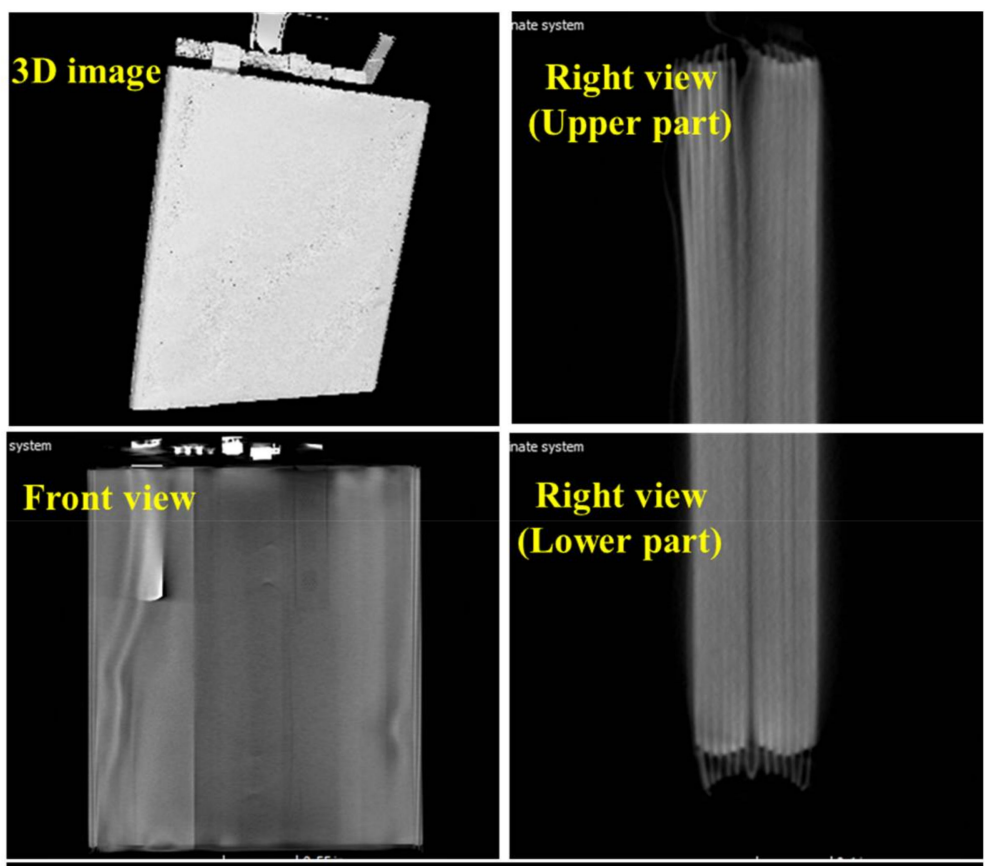

(Lower part)

\section{Top view}

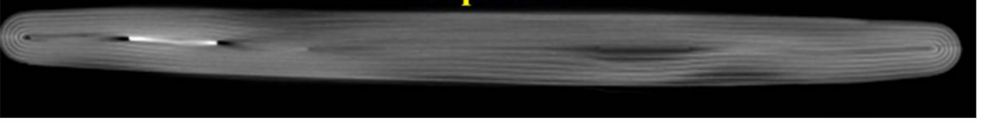

Figure 21. CT scan images of the battery from the used smartphone sample.

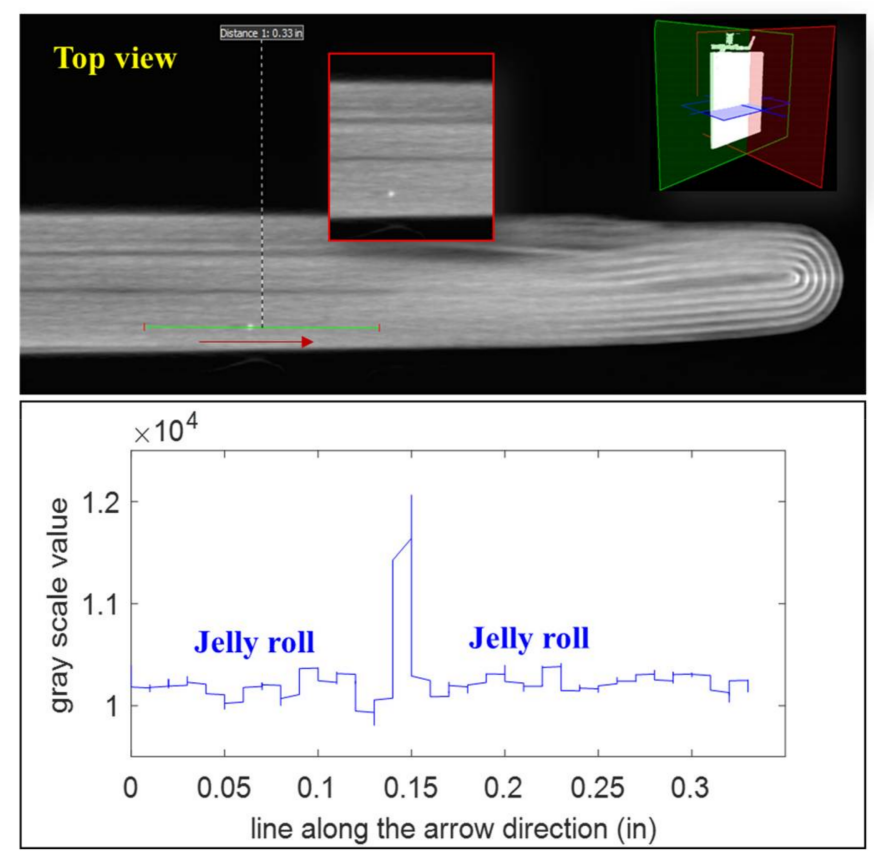

Figure 22. The point of interest in the battery from the used sample and the gray-scale profile along the marked green line crossing the point.

Figure 23 shows the 3D image, right, front and top views of the CT scan of the lithium-ion battery from the new smartphone. The electrode layers are uniformly arranged, and there are no signs of structural deformations as shown in Figure 20. 

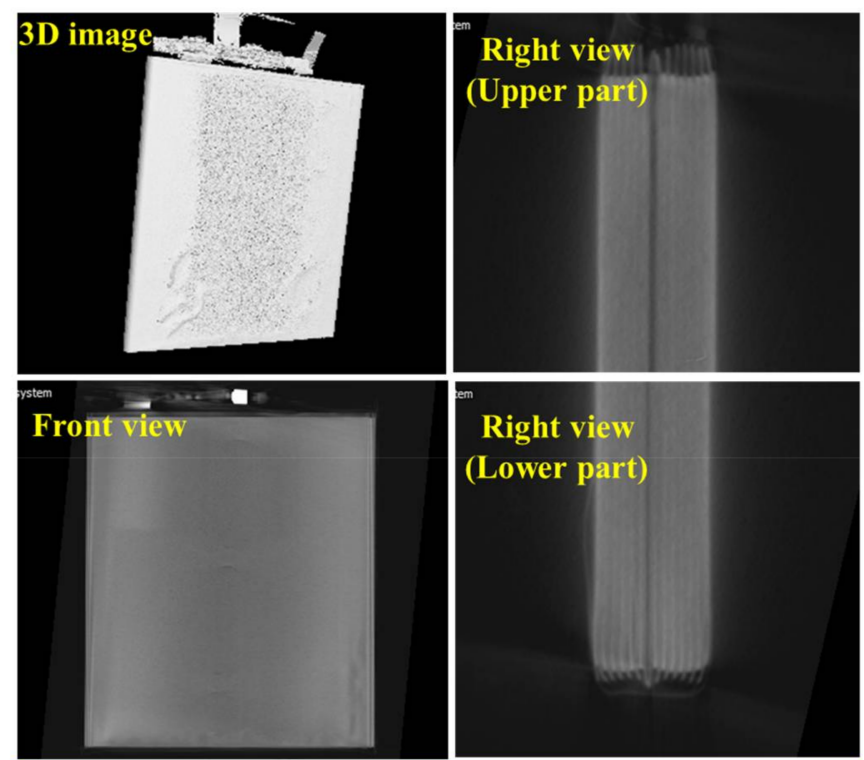

Top view

Figure 23. CT scan images of the battery from the new smartphone sample.

In Figure 24, two bright lines can be seen. These lines have been confirmed as ring artifacts [27,32]. Ring artifact occurs if one of the detector pixels is out of calibration or the pixels have defects or contaminations. These pixels will give incorrect gray-scale readings for each project, resulting in concentric rings in the reconstructed CT images. If the cause of the artifact is determined as out of calibration, the artifact can be eliminated by rescanning the battery after recalibration. However, if the artifact is due to the defective detector, it cannot be removed but can be mitigated using software filtering methods such as the median filter.

Except for ring artifacts, there are other common artifacts, such as edge enhancement and beam hardening. These artifacts are usually caused by imperfections in the scanner function, measurement noises, and reconstruction errors. They can seriously decrease the CT image quality and sometimes even lead to incorrect analysis results. A discussion of CT artifacts can be found in [32].
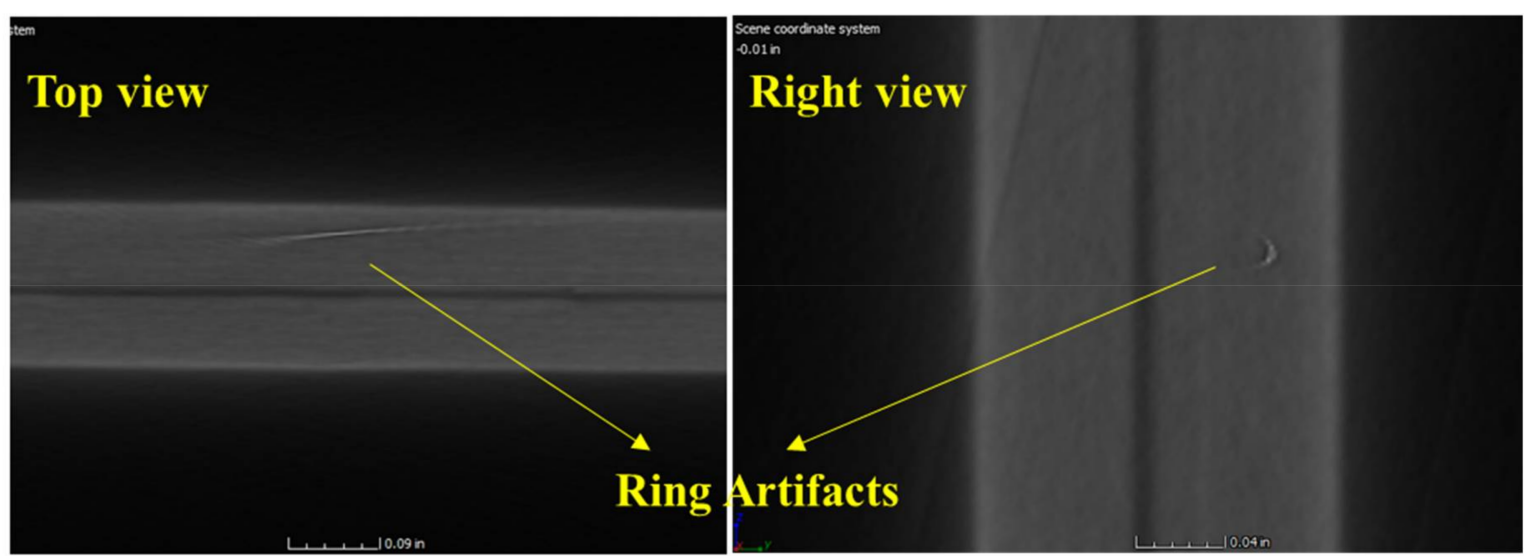

Figure 24. Location of the bright lines inside the battery from the new smartphone sample. 


\section{Conclusions}

Nondestructive methods play an important role in providing information on possible battery failure sites and causes without destroying the battery. Conventional nondestructive methods based on electrical testing of batteries are limited in terms of the failure information that they can provide and are not completely nondestructive because they are likely to put further stresses on the test samples. These methods are also not good at uncovering internal manufacturing defects, such as microscopic contaminants and defective components, because they focus on macroscopic battery performance.

CT scanning is a spatially nondestructive method for assessing a lithium-ion battery without changing the structure of the battery. It allows one to not only quantify material properties, but also to detect battery internal structural features, thus facilitating the identification of potential failures. This paper provided a practical guide on conducting CT scanning for lithium-ion battery analysis, including CT parameters selection and CT data interpretation. Furthermore, CT analysis was conducted for different types of lithium-ion batteries related to real e-cigarette and smartphone incidents. Various novel manufacturing-induced defects and structural deformations were discovered in these case studies.

For the 18650 cells associated with the first e-cigarette incident, welding burrs were observed on the negative tab for both the exploded and fresh cells from the same vendor. During battery charge/discharge, the normal swelling and contraction of the electrodes can force the welding burrs into the opposing positive electrode, causing the internal short circuit and resulting in overheating of the battery.

For the two fresh pouch cells associated with the second e-cigarette incident, three kinds of defects were found, including foreign particles, overlapping of two electrode tabs, and deflected electrodes. The foreign particles were identified using the CT qualitative measurement tool. The abnormal gray-scale values corresponding to these particles revealed the composition of these materials are different from other jelly roll materials. Such foreign particles and overlapping of electrode tabs can only be generated during the manufacturing process.

For smartphone cells, electrode deformations and foreign particles were found in the used smartphone cell using CT scanning. Such foreign particles are likely to induce a soft short circuit by diffusing into the separator pores or puncturing the separator. Additionally, ring artifacts were found in the CT scan images of the new smartphone cell, which represent a type of CT measurement error. The artifacts usually appear as concentric rings in the CT scan images and can be mitigated using some filtering and smoothing methods.

In summary, CT scanning is an effective nondestructive tool to detect the internal defects in lithium-ion batteries. It provides the ability for quality assessment of the battery manufacturing process and identifies the possible failure causes in manufacturing tests and in field use.

Acknowledgments: This work was supported by the National Natural Science Foundation of China [grant number 61473242]; Funding for Outstanding Doctoral Dissertation in NUAA [grant number BCXJ14-04]; Fundamental Research Funds for the Central Universities and Funding of Jiangsu Innovation Program for Graduate Education [grant number KYLX 0251]. The authors would like to thank the more than 150 companies and organizations that support research activities at the Center for Advanced Life Cycle Engineering (CALCE) at the University of Maryland.

Author Contributions: All authors contributed to the paper. Yi Wu, Saurabh Saxena and Michael Pecht wrote the paper; Michael Pecht also organized the paper and provided the battery samples; Yinjiao Xing performed the CT scan experiment and analyzed the CT scan results; Chuan Li contributed to the background research; Youren Wang and Winco K. C. Yung were responsible for revising the paper.

Conflicts of Interest: The authors declare no conflict of interest.

\section{References}

1. Schalkwijk, V.W.; Scrosati, B. Advances in Lithium-Ion Batteries; Springer Science \& Business Media: New York, NY, USA, 2007.

2. Armand, M.; Tarascon, J.M. Building better batteries. Nature 2008, 451, 652-657. [CrossRef] [PubMed] 
3. Williard, N.; He, W.; Hendricks, C.; Pecht, M. Lessons learned from the 787 Dreamliner issue on lithium-ion battery reliability. Energies 2013, 6, 4682-4695. [CrossRef]

4. Here Are the Reasons Why So Many Hoverboards Are Catching Fire. Available online: https:/ /www.cnet. $\mathrm{com} /$ news / why-are-hoverboards-exploding-and-catching-fire/ (accessed on 12 December 2017).

5. E-Cigarette Battery Explodes in Man's Pocket in Leeds Shopping Centre. Available online: http:/ / www.independent.co.uk/news/uk/e-cigarette-battery-explodes-vaping-catches-fire-leeds-trinityshopping-centre-boots-a7489826.html (accessed on 12 December 2017).

6. HP Recalls 101,000 Laptop Batteries over Fire Concerns. Available online: http://www.theverge.com/2017/ 1/25/14384052/hp-laptop-battery-recall-2017 (accessed on 18 July 2017).

7. Samsung Expands Recall to All Galaxy Note7 Devices. Available online: http://www.samsung.com/us / note7recall/ (accessed on 20 August 2017).

8. Beware the Bulgy Battery: Lithium-Ion Batteries Removed from Laptops Can Still Be Dangerous. Available online: https:/ / www.macworld.com/article/3162109/consumer-electronics/beware-the-bulgy-batterylithium-ion-batteries-removed-from-laptops-can-still-be-dangerous.html (accessed on 2 October 2017).

9. FDA Workshop to Examine Exploding E-Cigarettes. Available online: http:/ /www.cnn.com/2017/01/04/ health/e-cigarette-battery-fda-workshop/index.html (accessed on 17 November 2017).

10. Waldmann, T.; Iturrondobeitia, A.; Kasper, M.; Ghanbari, N.; Aguesse, F.; Bekaert, E.; Daniel, L.; Genies, S.; Gordon, I.J.; Löble, M.W.; et al. Review—Post-mortem analysis of aged lithium-ion batteries: Disassembly methodology and physico-chemical analysis techniques. J. Electrochem. Soc. 2016, 163, A2149-A2164. [CrossRef]

11. Williard, N.; Sood, B.; Osterman, M.; Pecht, M. Disassembly methodology for conducting failure analysis on lithium-ion batteries. J. Mater. Sci. Mater. Electron. 2011, 22, 1616-1630. [CrossRef]

12. Lambert, S.M.; Armstrong, M.; Attidekou, P.S.; Christensen, P.A.; Widmer, J.D.; Wang, C.; Scott, K. Rapid nondestructive-testing technique for in-line quality control of Li-ion batteries. IEEE Trans. Ind. Electron. 2017, 64, 4017-4026. [CrossRef]

13. Berecibar, M.; Gandiaga, I.; Villarreal, I.; Omar, N.; Van Mierlo, J.; Van den Bossche, P. Critical review of state of health estimation methods of Li-ion batteries for real applications. Renew. Sustain. Energy Rev. 2016, 56, 572-587. [CrossRef]

14. Li, Y.; Abdel-Monem, M.; Gopalakrishnan, R.; Berecibar, M.; Nanini-Maury, E.; Omar, N.; van den Bossche, P.; Van Mierlo, J. A quick on-line state of health estimation method for Li-ion battery with incremental capacity curves processed by Gaussian filter. J. Power Sources 2018, 373, 40-53. [CrossRef]

15. Gordon, I.A.J.; Grugeon, S.; Takenouti, H.; Tribollet, B.; Armand, M.; Davoisne, C.; Débart, A.; Laruelle, S. Electrochemical impedance spectroscopy response study of a commercial graphite-based negative electrode for Li-ion batteries as function of the cell state of charge and ageing. Electrochim. Acta 2017, 223, 63-73. [CrossRef]

16. Sazhin, S.V.; Dufek, E.J.; Gering, K.L. Enhancing Li-ion battery safety by early detection of nascent internal shorts. J. Electrochem. Soc. 2017, 164, A6281-A6287. [CrossRef]

17. Xiong, J.; Banvait, H.; Li, L.; Chen, Y.; Xie, J.; Liu, Y.; Wu, M.; Chen, J. Failure detection for over-discharged Li-ion batteries. In Proceedings of the 2012 IEEE International Electric Vehicle Conference, Greenville, SC, USA, 4-8 March 2012; IEEE: Piscataway, NJ, USA, 2012; pp. 1-5.

18. Hwang, J.-C.; Chen, J.-C.; Pan, J.-S.; Huang, Y.-C. Measurement method for online battery early faults precaution in uninterrupted power supply system. IET Electr. Power Appl. 2011, 5, 267-274. [CrossRef]

19. Chen, Z.; Xiong, R.; Tian, J.; Shang, X.; Lu, J. Model-based fault diagnosis approach on external short circuit of lithium-ion battery used in electric vehicles. Appl. Energy 2016, 184, 365-374. [CrossRef]

20. Maire, E.; Withers, P.J. Quantitative X-ray tomography. Int. Mater. Rev. 2014, 59, 1-43. [CrossRef]

21. Patrick, S.; Birur, N.P.; Gurushanth, K.; Raghavan, A.S.; Gurudath, S. Comparison of gray values of cone-beam computed tomography with hounsfield units of multislice computed tomography: An in vitro study. Indian J. Dent. Res. 2017, 28, 66-70. [CrossRef] [PubMed]

22. VDI-Group, The Association of German Engineers. VDI-Standard: VDI/VDE 2630 Blatt 1.2-Computed Tomography in Dimensional Measurement-Influencing Variables on Measurement Results and Recommendations for Computed Tomography Dimensional Measurements; VDI/VDE Society for Metrology and Automation Engineering: Düsseldorf, Germany, 2011. 
23. Villarraga-Gómez, H.; Lee, C.; Smith, S.T. Dimensional metrology with X-ray CT: A comparison with CMM measurements on internal features and compliant structures. Precis. Eng. 2017, 51, 291-307. [CrossRef]

24. Kruth, J.P.; Bartscher, M.; Carmignato, S.; Schmitt, R.; De Chiffre, L.; Weckenmann, A. Computed tomography for dimensional metrology. CIRP Ann. Manuf. Technol. 2011, 60, 821-842. [CrossRef]

25. Cantatore, A.; Müller, P. Introduction to Computed Tomography; DTU Mechanical Engineering: Kongens Lyngby, Denmark, 2011.

26. Soleimani, M.; Pengpen, T. Introduction: A brief overview of iterative algorithms in X-ray computed tomography. Philos. Trans. Ser. A Math. Phys. Eng. Sci. 2015, 373, 20140399. [CrossRef] [PubMed]

27. Pietsch, P.; Wood, V. X-ray tomography for lithium ion battery research: A practical guide. Annu. Rev. Mater. Res. 2017, 47, 451-479. [CrossRef]

28. Hubbell, J.H.; Seltzer, S.M. Tables of X-ray Mass Attenuation Coefficients and Mass Energy-Absorption Coefficients from $1 \mathrm{keV}$ to $20 \mathrm{MeV}$ for Elements $Z=1$ to 92 and 48 Additional Substances of Dosimetric Interest; NIST: Gaithersburg, MD, USA, 1995.

29. Wenig, P.; Stefan, K. Examination of the measurement uncertainty on dimensional measurements by $\mathrm{X}$-ray. In Proceedings of the 9th European Conference on Non-Destructive Testing (ECNDT), Berlin, Germany, 25-29 September 2006.

30. Cardoso, L.G.; Kawano, Y. Degradation of polyacrylonitrile by X-ray radiation. Polym. Degrad. Stab. 1994, 44, 27-32. [CrossRef]

31. Cnudde, V.; Boone, M.N. High-resolution X-ray computed tomography in geosciences: A review of the current technology and applications. Earth-Sci. Rev. 2013, 123, 1-17. [CrossRef]

32. Barrett, J.F.; Keat, N. Artifacts in CT: Recognition and avoidance. Radiographics 2004, 24, 1679-1691. [CrossRef] [PubMed]

33. De Chiffre, L.; Carmignato, S.; Kruth, J.P.; Schmitt, R.; Weckenmann, A. Industrial applications of computed tomography. CIRP Ann. Manuf. Technol. 2014, 63, 655-677. [CrossRef]

34. Mikolajczak, C.; Kahn, M.; White, K.; Long, R.T. Lithium Ion Batteries Hazard and Use Assessment; Fire Protection Research Foundation: Quincy, MA, USA, 2011.

35. Wang, H.; Watkins, T.R.; Simunovic, S.; Bingham, P.R.; Allu, S.; Turner, J.A. Fragmentation of copper current collectors in Li-ion batteries during spherical indentation. J. Power Sources 2017, 364, 432-436. [CrossRef]

36. Carter, R.; Huhman, B.; Love, C.T.; Zenyuk, I.V. X-ray computed tomography comparison of individual and parallel assembled commercial lithium iron phosphate batteries at end of life after high rate cycling. J. Power Sources 2018, 381, 46-55. [CrossRef]

37. Lamb, J.; Orendorff, C.J. Evaluation of mechanical abuse techniques in lithium ion batteries. J. Power Sources 2014, 247, 189-196. [CrossRef]

38. Waldmann, T.; Gorse, S.; Samtleben, T.; Schneider, G.; Knoblauch, V.; Wohlfahrt-Mehrens, M. A mechanical aging mechanism in lithium-ion batteries. J. Electrochem. Soc. 2014, 161, A1742-A1747. [CrossRef]

39. Yufit, V.; Shearing, P.; Hamilton, R.W.; Lee, P.D.; Wu, M.; Brandon, N.P. Investigation of lithium-ion polymer battery cell failure using X-ray computed tomography. Electrochem. Commun. 2011, 13, 608-610. [CrossRef]

40. Zhang, N.; Tang, H. Dissecting anode swelling in commercial lithium-ion batteries. J. Power Sources 2012, 218, 52-55. [CrossRef]

41. Finegan, D.P.; Scheel, M.; Robinson, J.B.; Tjaden, B.; Hunt, I.; Mason, T.J.; Millichamp, J.; Di Michiel, M.; Offer, G.J.; Hinds, G.; et al. In-operando high-speed tomography of lithium-ion batteries during thermal runaway. Nat. Commun. 2015, 6, 6924. [CrossRef] [PubMed]

42. Finegan, D.P.; Scheel, M.; Robinson, J.B.; Tjaden, B.; Di Michiel, M.; Hinds, G.; Brett, D.J.L.; Shearing, P.R. Investigating lithium-ion battery materials during overcharge-induced thermal runaway: An operando and multi-scale X-ray CT study. Phys. Chem. Chem. Phys. 2016, 18, 30912-30919. [CrossRef] [PubMed]

43. Bond, T.; Zhou, J.; Cutler, J. Electrode stack geometry changes during gas evolution in pouch-cell-type lithium ion batteries. J. Electrochem. Soc. 2017, 164, A6158-A6162. [CrossRef]

44. Samsung Galaxy Note 7 Explosions. Available online: http:/ / money.cnn.com/2016/10/11/technology / samsung-galaxy-note-7-discontinued/ (accessed on 20 August 2017).

45. Samsung Reveals Root Cause of Galaxy Note7 Battery Fires. Available online: http://www.anandtech.com/ show /11060/samsung-reveals-root-cause-of-galaxy-note7-battery-fires (accessed on 19 August 2017).

46. Hassan, S.; Anwar, M.U.; Muthayya, P.; Jivan, S. Burn injuries from exploding electronic cigarette batteries: An emerging public health hazard. J. Plast. Reconstr. Aesthet. Surg. 2016, 69, 1716-1718. [CrossRef] [PubMed] 
47. Nicoll, K.J.; Rose, A.M.; Khan, M.A.A.; Quaba, O.; Lowrie, A.G. Thigh burns from exploding e-cigarette lithium ion batteries: First case series. Burns 2016, 42, e42-e46. [CrossRef] [PubMed]

48. Mohanty, D.; Hockaday, E.; Li, J.; Hensley, D.K.; Daniel, C.; Wood, D.L. Effect of electrode manufacturing defects on electrochemical performance of lithium-ion batteries: Cognizance of the battery failure sources. J. Power Sources 2016, 312, 70-79. [CrossRef]

49. Google and Huawei Sued over Nexus 6P Bootloop and Battery Drain Issues. Available online: https: / / mobilesyrup.com/2017/04/20/google-and-huawei-sued-over-nexus-6p-bootloop-and-batterydrain-issues / (accessed on 12 July 2017).

50. Bootloops and Battery Issues Ruined the Nexus 6P and Are Definitely Cause for a Lawsuit. Available online: https:/ /yourtechexplained.com/2017/05/02/nexus-6p-bootloop-battery-issue-lawsuit/ (accessed on 12 July 2017).

(c) 2018 by the authors. Licensee MDPI, Basel, Switzerland. This article is an open access article distributed under the terms and conditions of the Creative Commons Attribution (CC BY) license (http://creativecommons.org/licenses/by/4.0/). 